\title{
Ultrasound-guided fine needle aspiration cytology as an addendum to sentinel lymph node biopsy can perfect the staging strategy in melanoma patients
}

Christiane A. Voit ${ }^{\mathrm{a}, \mathrm{e}, *, 1}$, Saskia L.M. Gooskens ${ }^{\mathrm{b}, \mathrm{e}, 1}$, Petra Siegel $^{\mathrm{a}}$, Gregor Schaefer ${ }^{\mathrm{a}}$, Alfred Schoengen ${ }^{\mathrm{c}}$, Joachim Röwert ${ }^{\mathrm{a}}$, Alexander C.J. van Akkooi ${ }^{\mathrm{b}, \mathrm{e}}$, Alexander M.M. Eggermont ${ }^{\mathrm{d}, \mathrm{e}}$

\footnotetext{
${ }^{a}$ Department of Dermatology, Charité, Humboldt University of Berlin, Berlin, Germany

${ }^{\mathrm{b}}$ Department of Surgical Oncology, Erasmus University Medical Center-Daniel den Hoed Cancer Center, Rotterdam, The Netherlands

${ }^{\mathrm{c}}$ Department of Hematology and Oncology, Armed Forces Hospital, Ulm, Germany

${ }^{\mathrm{d}}$ Institut de Cancérologie Gustav Roussy, Paris-Sud/Villejuif, France

${ }^{\mathrm{e}}$ European Organization for Research and Treatment of Cancer (EORTC) Melanoma Group (MG), Brussels, Belgium
}

Received 27 March 2014; received in revised form 28 May 2014; accepted 28 May 2014

Available online 3 July 2014

\author{
KEYWORDS \\ Melanoma \\ Sentinel node \\ Ultrasound \\ Fine needle aspiration \\ cytology \\ Survival \\ Prognosis
}

\begin{abstract}
Background: Ultrasound guided fine needle aspiration cytology (US-guided FNAC) can identify microscopic involvement of lymph nodes as in breast cancer and avoid surgical sentinel node ( $\mathrm{SN})$. Its utility in melanoma patients is controversial and subject of this study.

Methods: Between 2001 and 2010 over 1000 stage I/II consecutive melanoma patients prospectively underwent US-FNAC prior to SN biopsy. All patients underwent lymphoscintigraphy prior to US-FNAC. The Berlin US morphology criteria: Peripheral perfusion (PP), loss of central echoes (LCE) and balloon shaped (BS) were registered. FNAC was performed in case of presence of any of these factors. SN tumour burden was measured according to the Rotterdam criteria. All patients underwent SN or lymph node dissection (LND) in case of positive FNAC. Findings: Mean/median Breslow thickness was 2.58/1.57 mm. Mean/median follow-up was $56 / 53$ months (1-132). SN positivity rate was $21 \%$. US-FNAC Sensitivity was $71 \%$ (US only) and $51 \%$ (US-FNAC). Sensitivity of US-FNAC was highest for T4 (76\%) and ulcerated melanomas $(63 \%)$. PP, LCE and BS had sensitivity of $69 \%, 24 \%$ and $24 \%$ respectively. Sensitivity of
\end{abstract}

Ethical Approvals: \# 45/95 Ethics committee of the University of Ulm, \# 1367/00 of the Ethics Committee of the Charité, Medizinische Fakultät der Humboldt Universität Berlin and Amendment EA1/023/06.

* Corresponding author at: Department of Dermatology, Charité, University Medicine, Berlin, Charitéplatz 1, 10117 Berlin, Germany. Tel.: +49 30450 618230; fax: +49 9491952616.

E-mail address: christiane.voit@t-online.de (C.A. Voit).

${ }^{1}$ Shared first authorship. 
US-FNAC increased with increasing SN tumour burden. PP was an early sign of metastasis ( $58 \%$ in $<0.1 \mathrm{~mm}$ metastases). Threshold size of a metastasis for FNAC was $0.3 \mathrm{~mm}$. Five-year survival correlated to US-FNAC status ( $95 \%$ in negative and $59 \%$ in positive).

Interpretation: Ultrasound guided FNAC (US-FNAC) according to the Berlin morphology criteria could correctly identify at least half of all tumour positive sentinel nodes, prior to the surgical SN procedure. Peripheral perfusion is an early sign of metastasis, which is very sensitive, but with lower positive predictive value (PPV). It is responsible for the sensitivity of the procedure. Balloon shape is a sign of advanced metastases, with lower sensitivity, but high PPV. US-FNAC sensitivity correlated with increasing T-stage, ulceration of the primary and increasing SN tumour burden. US-FNAC status accurately predicts survival.

(C) 2014 Elsevier Ltd. All rights reserved.

\section{Introduction}

Over recent decades the incidence of malignant melanoma has been rising throughout Europe, the United States of America (USA) and Australia [1-4], but mortality has remained virtually unchanged [4].

The most important prognostic factor of early stage melanomas (stage I/II) is lymph nodal status. Therefore, adequate staging of these patients is very important to be able to determine their prognosis $[5,6]$. Worldwide, the sentinel node (SN) procedure has been accepted during the past two decades as the most accurate staging procedure [7]. Sentinel node biopsy (SNB) is a surgical procedure with a complication rate between $5 \%$ and $10 \%[8,9]$. In the absence of proof that SNB is associated with a survival benefit alternative methods to identify positive SNs are being considered. The diagnostic algorithm of other cancers, such as thyroid and breast cancer, already includes pre-operative ultrasound (US) and fine needle aspiration cytology (FNAC) and it is conceivable to apply this to melanomas.

Previously, we have demonstrated that ultrasound can identify the same node, which is later excised and considered the sentinel node with an accuracy of $79 \%$ [10]. Another study by our group has demonstrated that US-FNAC could identify up to $65 \%$ of all SN involvement preoperatively [11]. Finally, we have described specific US patterns, which were used to achieve such a high sensitivity, the so called Berlin morphology criteria, which include Peripheral perfusion (PP) as an early sign of involvement followed by loss of central echo (LCE) and balloon shape (BS) as signs of advanced involvement [12].

The number of evaluated patients and their mean and median follow-up have increased significantly. The aim of the current study was to evaluate our increased experience with this modern approach comprising the highest amount of US-FNAC of SNs and to test its application as a completion to SNB. This is especially en vogue with the background of the just now published results of the MSLT1 trial [13], which is literally a confirmation of the results in 2006 and the importance of the non-sentinel node status, which can be assessed by performing completion lymph node dissection (CLND) after a positive sentinel lymph node biopsy (SLNB) [14]; or even - as an alternative-directly after a positive FNAC of the sentinel node.

\section{Patient and methods}

\subsection{Patients}

Our prospectively collected database includes all patients presenting with a histopathologically proven primary malignant melanoma (at least $1.00 \mathrm{~mm}$ Breslow thickness, or if less, at least Clark IV/V, ulcerated and/or regressed) and who were planned for a sentinel node procedure at the Department of Dermatology, Charité, University Medicine Berlin, Germany. The institutional ethics review board (ERB) approved the study and informed consent was obtained from all patients enrolled. Recruitment for this study started in 2001, the database now includes over 1500 patients. For the current analyses, we have censored inclusion after the first 1000 consecutive patients with sufficient follow-up (July 2001-November 2010). This cohort includes the first 400 patients, which have been examined exclusively by one ultrasonographist $(\mathrm{CV})$ and whose results have been previously published elsewhere $[11,12]$.

\subsection{Methods}

All patients were scheduled for a $\mathrm{SN}$ procedure in either 1 or 2 day protocol. Patients first underwent a lymphoscintigraphy, which assists the ultrasonographist to better focus their examination. In the timeslot between lymphoscintigraphy and surgery, patients were examined by ultrasound (US) in B-mode and Power Doppler. US is aimed at clearly depicting the location of the suspected SN and at clearly stating whether it seemed to be involved or not. If US depicted a suspicious or malignant SN, FNAC was performed (3-4 repeat FNACs were performed within one procedure) for verification of the lesion. If a clearly malignant 
ultrasound pattern could not be verified by FNAC, patients proceeded to undergo a SN. In the early phase of the study, all patients with positive FNAC proceeded to undergo a SN nonetheless ( $n=47$ ). During the course of the study, a change in hospital policy allowed the surgeon to proceed to an immediate CLND after a positive FNAC. The decision to change a planned SN to a CLND was always based on a positive cytology. US patterns are collected into the prospective database prior to gathering of the cytology and histopathology results. If the US does not show any suspicious nodes or if cytology is negative, the patients proceed to undergo the scheduled SN as described before $[11,12]$. Microanatomic location of metastases is evaluated according to the criteria by Dewar et al. [15]. SN tumour burden is assessed according to the Rotterdam criteria for SN tumour burden [16,17]. Final histology of the SN or LND was considered as the golden standard.

\subsection{Ultrasound technique and image analysis}

All US examinations were performed using the highend device MyLab 70 (ESAOTE, Genova, Italy) equipped with three transducers $(1-18 \mathrm{MHz}$ ) (B-mode, 30 pictures per second, colour Doppler, Power Mode). The lymph node was measured, the pattern was described and it was classified as benign [b], suspicious [s] or malignant $[\mathrm{m}]$ by an expert ultrasonographist (C.V.). During the course of the study, two additional and less extensively trained ultrasonographists were integrated into the team. An ultrasound was considered suspicious, when Peripheral perfusion (PP) was present or if the central echo was wandering towards the rim [12]. US was considered malignant if there was a total loss of central echoes (LCE) or if the lymph node was enlarged and balloon shaped (BS) [12]. If none of these morphological criteria were present, the lymph node was considered benign [12]. Details of the ultrasound morphology criteria have been described [12].

Of the 1000 patients, patients' images have been saved as jpg.data and were analysed by two experts using a computerised workstation (ESAOTE, Genova, Italy). Nodal size was calculated as described previously [12].

\subsection{Fine needle aspiration in detail}

FNAC was performed with a hand-held Binder-valve as described in detail elsewhere [18]. The fine needle for superficial lymph nodes has a diameter of approximately $0.4 \mathrm{~mm}(26 \mathrm{G})$, especially for small targets. A smear is considered technically efficient, if it contained approximately 100 cells.

Cytologic results were reported to the surgeons and it was left to their discretion how to proceed with surgery, either SN or LND. If the US did not show any suspicious nodes or if the cytology was negative, the patients proceeded to undergo the scheduled SN.

\subsection{Histopathological evaluation of excised $S N$}

In brief, lymph nodes were fixed for $24 \mathrm{~h}$ in buffered formalin. After fixation they were cut in half through the hilum and its longest dimension and embedded in paraffin. In rare cases, exceptionally large nodes were sectioned parallel to the first cut in order to fit in the blocks. Five serial step sections of $4 \mu \mathrm{m}$ each were cut from each face of the lymph node, and staining with H\&E, S100 and HMB-45 was performed. Microanatomic location of the metastases and SN tumour burden were assessed according to the Dewar and Rotterdam criteria, respectively $[15,16]$.

\subsection{Statistics}

To assess the diagnostic value of individual and combinations of US patterns for involved sentinel nodes, sensitivity and specificity of those patterns as well as positive or negative predictive values were calculated. Associations were tested with Pearson's chi square test. Disease-free survival (DFS) and Melanoma specific survival (MSS) were calculated from SN date until death or censored at the date of last known follow-up, if no events had taken place. Univariate analyses of survival were performed using the Kaplan-Meier method and the log-rank test. Multivariate analyses to determine the prognostic value of covariates regarding survival were performed using the Cox's proportional hazard model. Statistical analyses were all performed with Stata $^{\circledR}$, version 11.0 (Stata Corporation, College Station, Texas, USA). $P$ values of less than 0.05 were considered as significant.

\section{Results}

Baseline characteristics of all 1000 patients are described in Table 1. Mean and median age was 59 and 62 years, respectively (range 15-94 years). Mean and median Breslow thickness was $2.58 / 1.57 \mathrm{~mm}$ $(0.2-44 \mathrm{~mm})$. Ulceration was present in $24 \%$ of primary melanomas. In total 208 patients $(21 \%)$ had positive lymph node disease on histology, either after positive SN ( $n=165,17 \%$ of total, $79 \%$ of all lymph node diseases) or directly proceeded to LND (after positive US-FNAC) in 43 cases ( $4 \%$ of total, $21 \%$ of all lymph node diseases). The chance for lymph nodal involvement increased with increasing T-stage; $5 \%(15 / 288)$ for T1, 12\% (37/308) for $\mathrm{T} 2,32 \%(73 / 231)$ for $\mathrm{T} 3$ and $48 \%(83 / 173)$ for $\mathrm{T} 4$, respectively $(P<0.001)$.

Mean and median follow-up of the total patient population was 56 and 53 months, respectively (range 
Table 1

Baseline patient, tumour and follow-up characteristics of all 1000 patients.

\begin{tabular}{|c|c|c|c|}
\hline Characteristic & $N(\%)$ & Characteristic & $N(\%)$ \\
\hline \multicolumn{2}{|l|}{ Gender } & \multicolumn{2}{|l|}{ Sentinel nodes (SNs)s removed } \\
\hline Male & $567(57 \%)$ & Mean/median (range) & $1.72 / 1(1-13)$ \\
\hline Female & $433(43 \%)$ & SN result & \\
\hline \multicolumn{2}{|l|}{ Histological subtype } & \multirow[t]{2}{*}{ Negative } & 792 \\
\hline \multirow{3}{*}{$\begin{array}{l}\text { Superficial soreading melanoma } \\
\text { (SSM) }\end{array}$} & & & $79 \%$ \\
\hline & \multirow[t]{2}{*}{$595(60 \%)$} & \multirow[t]{2}{*}{ Positive } & 208 \\
\hline & & & $21 \%$ \\
\hline \multirow[t]{2}{*}{ Nodular melanoma (NM) } & \multirow[t]{2}{*}{$242(24 \%)$} & \multirow[t]{2}{*}{ Direct LND (after pos FNAC) } & $43(4 \%)$ \\
\hline & & & $43 / 208(21 \%)$ \\
\hline Lentigo maligna melanoma (LMM) & $37(4 \%)$ & \multicolumn{2}{|c|}{ SN tumour burden according to Rotterdam criteria } \\
\hline \multirow[t]{2}{*}{ Acrolentigous melanoma (ALM) } & $44(4 \%)$ & $\leqslant 0.1 \mathrm{~mm}$ & $30(\# \%)$ \\
\hline & & & $30 / 208(14 \%)$ \\
\hline \multirow[t]{2}{*}{ Unknown } & $82(8 \%)$ & $0.1-1.0 \mathrm{~mm}$ & $62(6 \%)$ \\
\hline & & & $62 / 208(30 \%)$ \\
\hline \multirow[t]{2}{*}{ Breslow thickness } & & $>1.0 \mathrm{~mm}$ & $62(6 \%)$ \\
\hline & & & $62 / 208(30 \%)$ \\
\hline \multirow[t]{2}{*}{ Mean/median (range) } & $2.58 / 1.57 \mathrm{~mm}(0.2-44 \mathrm{~mm})$ & LND/unknown & $54(5 \%)$ \\
\hline & & & $54 / 208(26 \%)$ \\
\hline $\mathrm{T} 1(\leqslant 1.00 \mathrm{~mm})$ & $288(29 \%)$ & Peripheral perfusion & \\
\hline $\mathrm{T} 2(1.01-2.00 \mathrm{~mm})$ & $308(31 \%)$ & Absent & $663(66 \%)$ \\
\hline $\mathrm{T} 3(2.01-4.00 \mathrm{~mm})$ & $231(23 \%)$ & Present & $273(27 \%)$ \\
\hline $\mathrm{T} 4(>4.00 \mathrm{~mm})$ & $173(17 \%)$ & Unknown & $64(7 \%)$ \\
\hline \multicolumn{2}{|l|}{ Ulceration } & \multicolumn{2}{|l|}{ Loss of central echo (LCE) } \\
\hline Absent & $758(76 \%)$ & Central echo present (normal) & $791(79 \%)$ \\
\hline Present & $242(24 \%)$ & Wandering to rim & $97(10 \%)$ \\
\hline \multicolumn{2}{|l|}{ Regression } & Lost & $66(6 \%)$ \\
\hline Absent & $633(63 \%)$ & Unknown & $46(5 \%)$ \\
\hline Present & $300(30 \%)$ & Balloon shape (BS) & \\
\hline Unknown & $67(7 \%)$ & Absent & $881(88 \%)$ \\
\hline \multicolumn{2}{|l|}{ Clark level } & Present & $53(5 \%)$ \\
\hline II & $32(3 \%)$ & Unknown & $66(7 \%)$ \\
\hline III & $341(34 \%)$ & \multicolumn{2}{|c|}{ Ultrasound guided fine needle aspiration cytology (US-FNAC) results } \\
\hline \multirow[t]{2}{*}{ IV } & $554(56 \%)$ & Not performed \& negative/negative & $892 / 342$ \\
\hline & & & $89 \% / 34 \%$ \\
\hline \multirow[t]{2}{*}{$\mathrm{V}$} & $54(6 \%)$ & Positive & $98(10 \%)$ \\
\hline & & & $98 / 342(26 \%)$ \\
\hline Unknown & $13(1 \%)$ & & \\
\hline
\end{tabular}

1-132 months). There were 198 patients $(20 \%)$ with recurrences and 81 melanoma related deaths $(8 \%)$ during this follow-up.

The sensitivity of US alone was $71 \%$. Sensitivity of US-FNAC (positive FNAC and/or clearly malignant US) and different subgroups are described in Table 2. The general combination of US-FNAC yielded a sensitivity of $51 \%$, with a specificity of $99 \%$, a PPV of $99 \%$ and a negative predictive value (NPV) of $89 \%$ $(P<0.001)$. This means that $72 \%$ of lesions correctly identified by ultrasound, could be confirmed by a positive FNAC and $28 \%$ could not.

Sensitivity of US-FNAC was highest for T4 tumours $(76 \%) \quad(P<0.001)$, ulcerated $(63 \%) \quad(P<0.001)$ and Peripheral perfusion $(69 \%)(P<0.001)$. PPV was highest for balloon shaped $(92 \%)$ when compared to PP $(51 \%)$ or LCE $(73 \%)(P<0.001)$. There was one patient with a false positive FNAC, based on cytology that eventually turned out to correspond to a negative SN. However, this patient returned with a lymph node relapse 1 year later.

FNAC was performed in $342 / 1000$ patients $(34 \%)$. This was in 172/416 (41.3\%) of extremity (arm or leg) melanomas, $139 / 471$ (29.5\%) of trunk melanomas and 31/113 $(27.4 \%)$ of head \& neck melanomas, respectively. In 98/ 342 patients the FNAC was positive (26\%). Thus, 1:4 patients, who had a suspicious or malignant US, had a positive FNAC. Ten patients $(n=10)$ with clearly malignant US morphology did not undergo FNAC, because there was no time between US and the SN procedure. Together we consider 108 patients (98 FNAC positive and 10 US clearly malignant) as US-FNAC positive.

Another sixteen $(n=16)$ patients with a merely suspicious ultrasound, did not undergo a FNAC due to the same above mentioned reason (total 3\%). These cases were treated as FNAC negative. The majority of 
Table 2

Sensitivity, specificity, positive predictive values and negative predictive values for ultrasound guided fine needle aspiration cytology (USFNAC) per T-stage, ulceration, separate morphology criterion and US-FNAC combination.

\begin{tabular}{|c|c|c|c|c|}
\hline & Sensitivity & Specificity & PPV & NPV \\
\hline \multicolumn{5}{|l|}{ T-stage } \\
\hline $\mathrm{T} 1$ & $40 \%$ & $100 \%$ & $100 \%$ & $97 \%$ \\
\hline $\mathrm{T} 2$ & $24 \%$ & $99 \%$ & $90 \%$ & $91 \%$ \\
\hline $\mathrm{T} 3$ & $40 \%$ & $100 \%$ & $100 \%$ & $78 \%$ \\
\hline $\mathrm{T} 4$ & $76 \%$ & $100 \%$ & $100 \%$ & $82 \%$ \\
\hline \multicolumn{5}{|l|}{ Ulceration } \\
\hline Absent & $43 \%$ & $99 \%$ & $98 \%$ & $90 \%$ \\
\hline Present & $63 \%$ & $100 \%$ & $100 \%$ & $83 \%$ \\
\hline \multicolumn{5}{|l|}{ Ultrasound morphology criteria } \\
\hline Peripheral perfusion (PP) & $69 \%$ & $82 \%$ & $51 \%$ & $91 \%$ \\
\hline Echo wandering to rim & $23 \%$ & $91 \%$ & $47 \%$ & $86 \%$ \\
\hline Loss of central echo (LCE) & $24 \%$ & $91 \%$ & $73 \%$ & $86 \%$ \\
\hline LCE \& wandering to rim & $46 \%$ & $91 \%$ & $58 \%$ & $86 \%$ \\
\hline Balloon shape (BS) & $24 \%$ & $99 \%$ & $92 \%$ & $83 \%$ \\
\hline US-FNAC total & $51 \%$ & $99 \%$ & $99 \%$ & $89 \%$ \\
\hline
\end{tabular}

Table 3

Ultrasound guided fine needle aspiration cytology (US-FNAC) per sentinel node ( $\mathrm{SN})$ tumour burden.

\begin{tabular}{cccccc}
\hline & $\begin{array}{c}\mathrm{SN} \\
\text { neg }\end{array}$ & $\leqslant 0.1 \mathrm{~mm}$ & $0.1-1.0 \mathrm{~mm}$ & $>1.0 \mathrm{~mm}$ & $\begin{array}{l}\mathrm{LND} / \\
\text { unknown }\end{array}$ \\
\hline $\begin{array}{c}\text { US-FNAC } \\
\text { neg }\end{array}$ & $99 \%$ & $83 \%$ & $76 \%$ & $39 \%$ & $9 \%$ \\
$\begin{array}{c}\text { US-FNAC } \\
\text { pos }\end{array}$ & $1 \%$ & $17 \%$ & $24 \%$ & $61 \%$ & $91 \%$ \\
\hline
\end{tabular}

patients $(63 \%)$, those with a benign ultrasound, did not need to undergo a FNAC in this study (Fig. 1S).

Of the 658 patients, who had a benign US or did not have time to undergo a FNAC, 64 patients $(10 \%)$ had a positive SN (False Negatives), whereas in the group of patients with a suspicious or malignant US result and negative FNAC, the SN was positive in 56/253 cases $(22 \%)$. Thus the chance for a positive $\mathrm{SN}$ in the group of patients without FNAC or negative FNAC results was twice as high in case of a suspicious or malignant US compared to a benign US result (chance twice as high for False Negative).

The correct detection by US-FNAC increased with increasing SN tumour burden. 17\% of patients with SN tumour burden $<0.1 \mathrm{~mm}$ were detected by USFNAC compared to $24 \%$ in lesion of $0.1-1.0 \mathrm{~mm}$ and $61 \%$ of lesions $>1.0 \mathrm{~mm}$. Detection was $91 \%$ in patients who proceeded directly to LND or had unknown SN tumour burden (Table 3). The detection limit (smallest diameter of SN metastasis) for a positive FNAC was $0.3 \mathrm{~mm}$.

5-Year Kaplan-Meier estimated melanoma specific survival (MSS) was 95\% for US-FNAC negative patients, compared to $59 \%$ for US-FNAC positive patients, respectively $(P<0.001)$ (Fig. 1A). The corresponding Kaplan-Meier estimated 5-year disease-free survival (DFS) rates were $84 \%$ for US-FNAC negative patients versus $33 \%$ for US-FNAC positive patients $(P<0.001)$ (Fig. 1B).

The 5-year Kaplan-Meier estimated MSS with negative Berlin morphology criteria (no malignant or suspicious ultrasound findings) was $96 \%$ versus $89 \%$ for Peripheral perfusion (PP) only or central echo wandering to the rim $(P<0.001)$ (Fig. 2A). Balloon shape (BS) or complete loss of central echo (LCE) yielded a 59\% 5-year Kaplan-Meier estimated MSS $(P<0.001)$ (Fig. 2A). Corresponding Kaplan-Meier estimated 5-year DFS was $85 \%$ for negative patients versus $74 \%$ for $\mathrm{PP}$ or central echo wandering to the rim $(P<0.001)$ and $36 \%$ for BS and/or LCE $(P<0.001)$ (Fig. 2B).

5-Year Kaplan-Meier estimated MSS per SN tumour burden was $96 \%$ for SN negative patients versus $100 \%$ for patients with metastases $<0.1 \mathrm{~mm}$ in maximum diameter according to the Rotterdam criteria (n.s.) (Fig. 3A). Patients with metastases $0.1-1.0 \mathrm{~mm}$ had a $73 \%(P<0.001) 5$-year Kaplan-Meier estimated MSS,
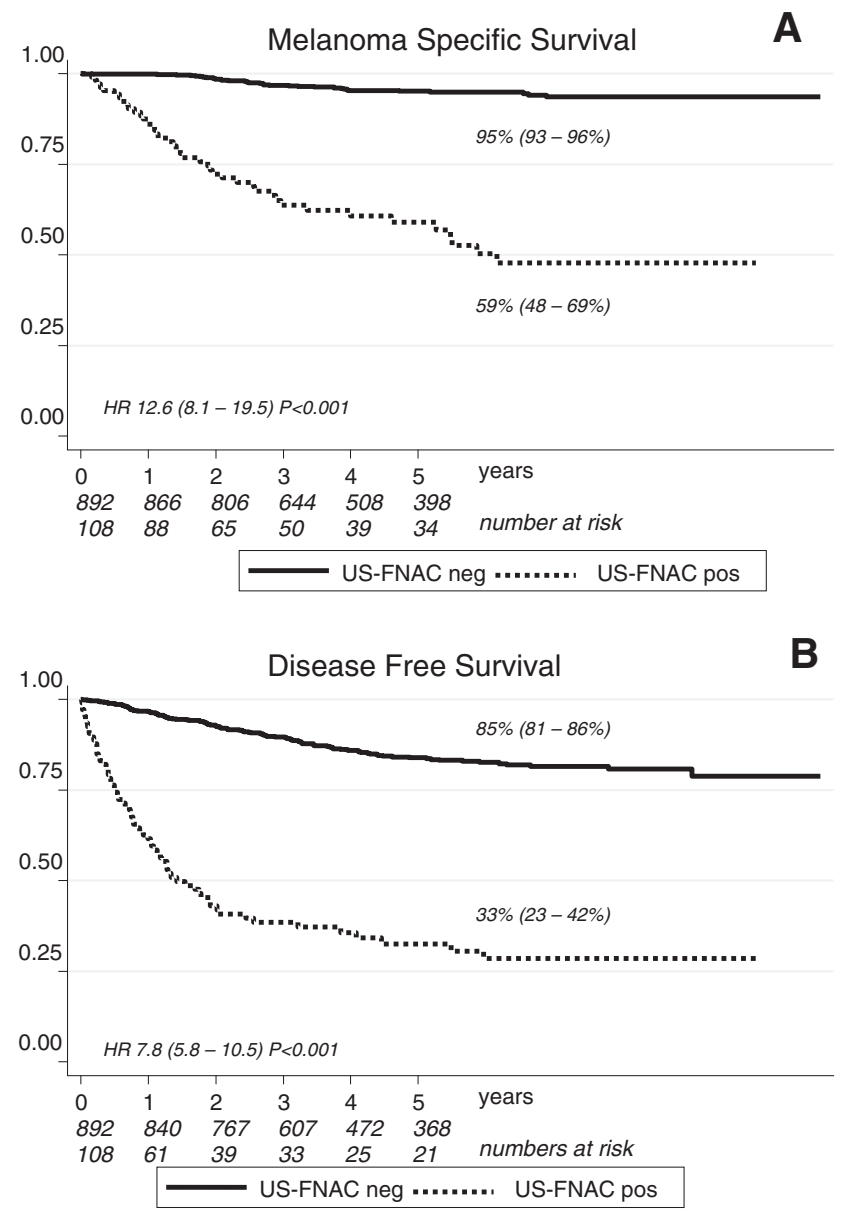

Fig. 1. Melanoma specific survival (A) and disease-free survival (B) according to ultrasound guided fine needle aspiration cytology (USFNAC) status. 
patients with lesions $>1.0 \mathrm{~mm}$ had a $68 \%(P<0.001)$ 5 -year MSS and patients with a LND or unknown SN tumour burden had a 5 -year MSS of $57 \%(P<0.001)$ (Fig. 3A). Corresponding Kaplan-Meier estimated 5-year DFS rates were $87 \%$ for SN negative patients compared to $83 \%$ for patients with $<0.1 \mathrm{~mm}$ lesions $(P=0.45)$ versus $49 \%$ in patients with lesions $0.1-1.0 \mathrm{~mm}$ $(P<0.001)$ versus $37 \%$ for patients with lesions $>1.0 \mathrm{~mm}$ $(P<0.001)$ versus $33 \%$ for $\mathrm{LND}$ or unknown $\mathrm{SN}$ tumour burden patients $(P<0.001)$ (Fig. 3B).

\section{Discussion}

Diagnosis of lymph node metastases at the time of SNB has several potential benefits, including more accurate prognostic information, enhanced nodal control and disease-free survival, and improvement in overall survival. However, there is uniformity in agreement that SNB yields the first two benefits, but improvement in overall survival has never been conclusively demonstrated [19]. This present study showed that ultrasound
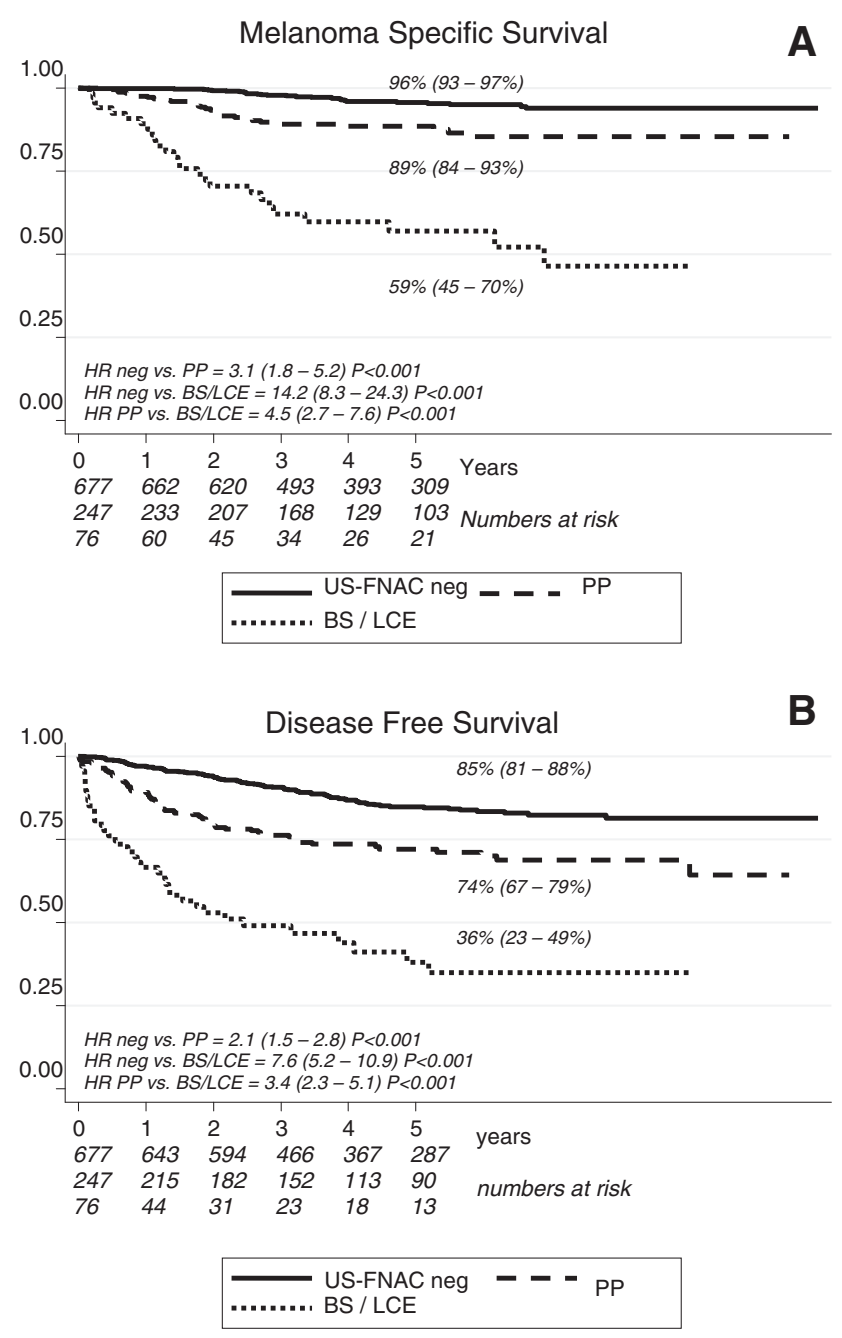

Fig. 2. Melanoma specific survival (A) and disease-free survival (B) according to Berlin ultrasound morphology criteria. alone is able to identify up to $71 \%$ of SN metastases preoperatively. FNAC confirmation leads to a correct detection rate of $51 \%$ of involved sentinel nodes, prior to their surgical removal $[11,12]$. Sensitivity is higher for subgroups of patients with a priori risk factors for nodal involvement, such as high Breslow thickness (T4) or ulceration of the primary, with sensitivity of $76 \%$ and $61 \%$, respectively. Likewise, the volume of SN tumour burden also affected the sensitivity of US-FNAC, with sensitivity of $17 \%$ in $\leqslant 0.1 \mathrm{~mm}$ metastases versus $61 \%$ in metastases $>1.0 \mathrm{~mm}$ in maximum diameter.

Peripheral perfusion (PP) had a high sensitivity (69\%) and was potentially capable of detecting a high proportion of metastases, including small and early metastases, but had a low PPV (51\%) and relatively low specificity (81\%).

Balloon shape (BS) and loss of central echo (LCE) had a low sensitivity (25\%), but high PPV (92\%). This means that it detects only relatively few metastases
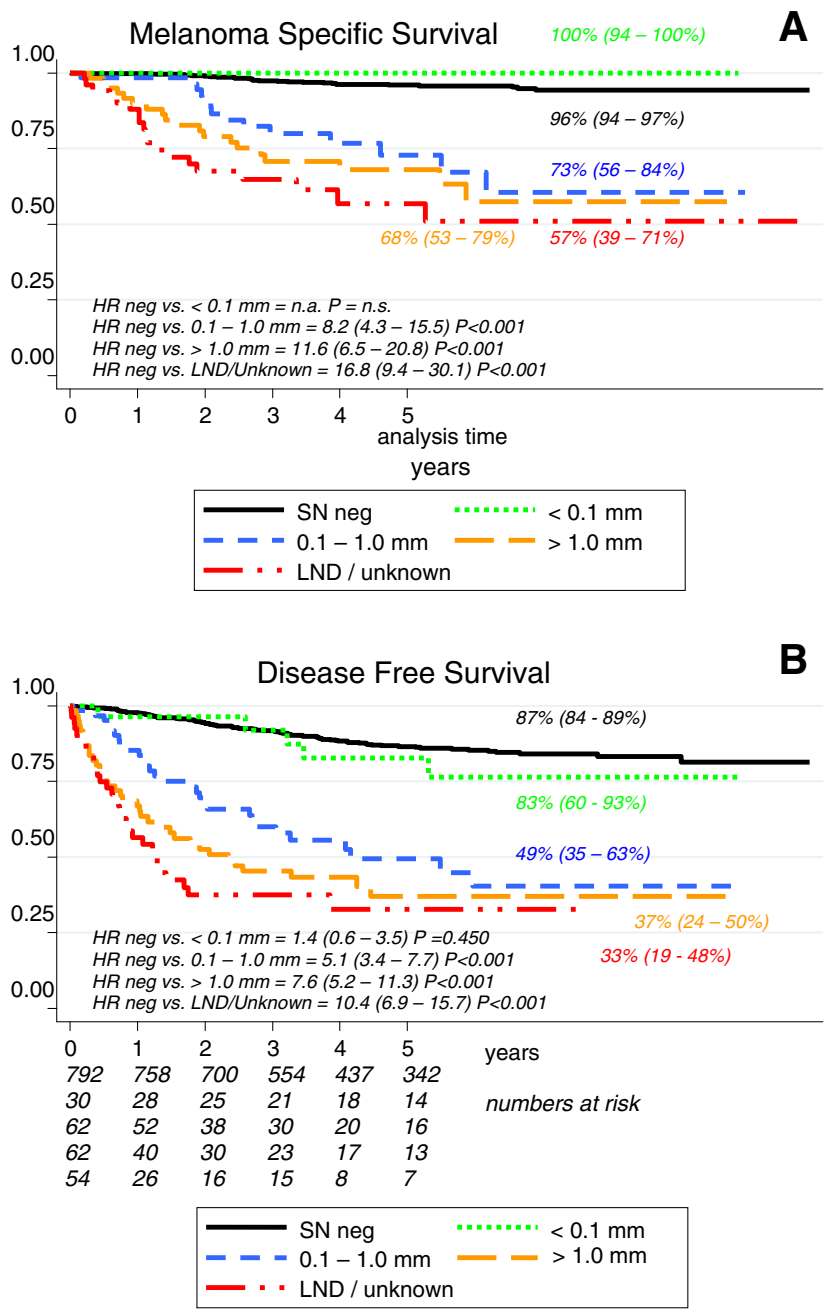

Fig. 3. Melanoma specific survival (A) and disease-free survival (B) according to sentinel node ( $\mathrm{SN}$ ) tumour burden according to the Rotterdam criteria. 


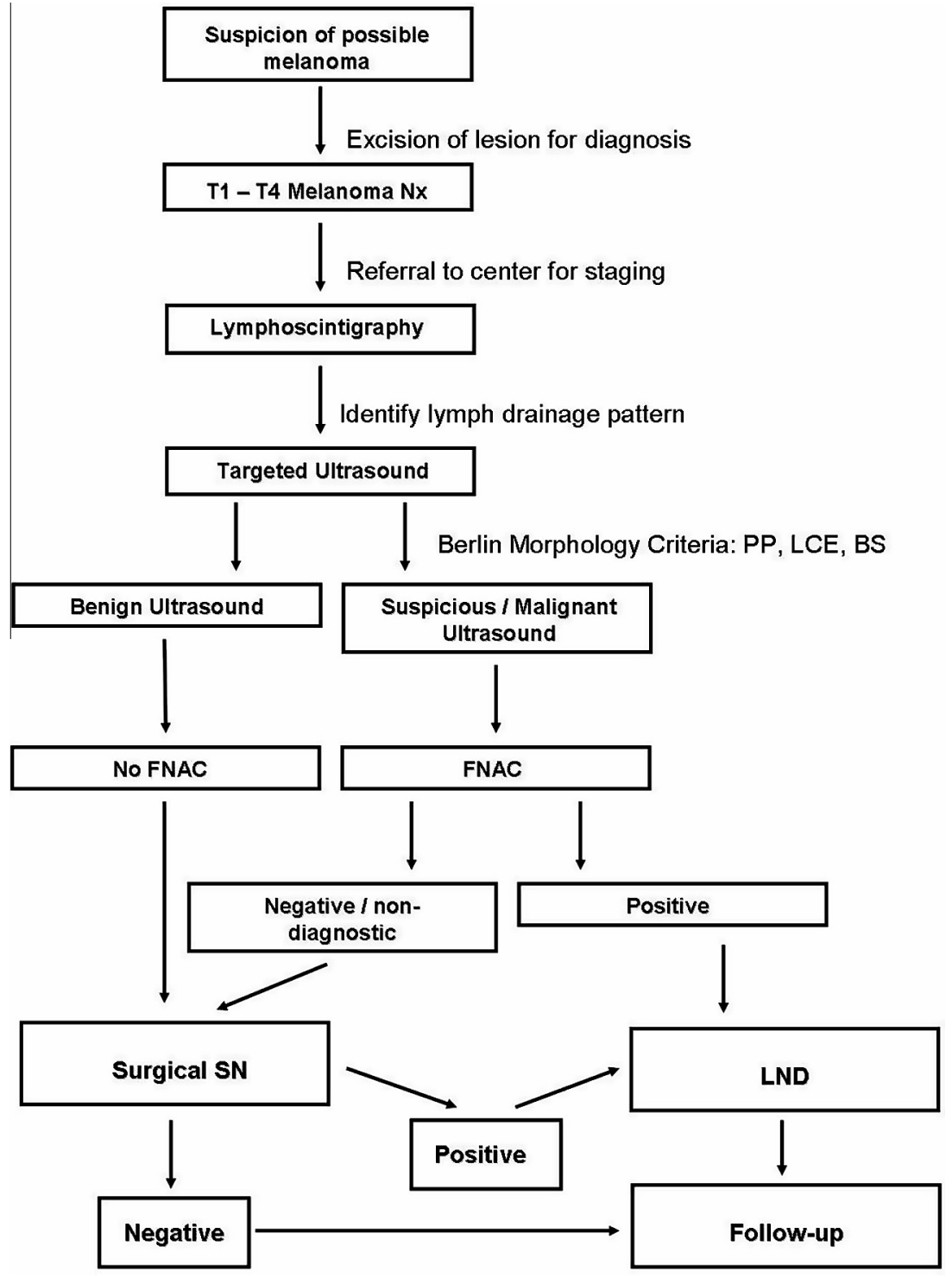

Fig. 4. Diagnostic (staging) algorithm.

(because most of the $\mathrm{SN}$ node metastases are small in size and do not present with these late patterns), but if these criteria are seen, the chance that the lesion is malignant is very high, and consequently, these criteria correlate to larger (late) metastases.

Sensitivity is lower than our previously reported experience of the first 400 patients, which had demonstrated $65 \%$ sensitivity $[11,12]$. The sensitivity declined for the general combination of US-FNAC, but also for all subgroups of morphological criteria. This can be explained by the fact the US-FNAC is operator dependent and that all 400 procedures were performed by the senior ultrasonographist (CV), whereas the next 600 were performed by two further examiners. The results vary and the learning curves differ (results not shown).

Nevertheless, a $51 \%$ sensitivity can potentially spare $10 \%$ of all melanoma patients undergoing a SN procedure this unnecessary procedure and obvously can spare half of positive SN patients this unnecessary procedure.
The $\mathrm{SN}$ procedure is a minimally invasive staging procedure, which does not have the potential high rates of major and/or chronic complications as a CLND, but it is a surgical procedure with potential morbidity nonetheless in contrast to FNAC, which is almost never associated with any morbidity. Wound infections, seromas, bleeding and even in incidental case chronic lymph oedema have been described [7,20-22]. Also the additional anaesthesia and costs could potentially be spared. Our group previously calculated that serial US-FNAC could potentially save up to $55 \%$ of the costs compared to surgical SN staging in these patients [23].

When compared to the literature, the sensitivity in our hands $(51 \%)$ is significantly higher than previously reported rates, which differ from $4 \%$ to $39 \%$ [24-29]. In these relatively small series, Starritt et al. achieved a sensitivity of $21 \%$ (7/33), van Rijk et al. achieved $34 \%$ $(12 / 37)$ and Rossi et al. achieved a rate of $39 \%$ $(12 / 31)$. A recent small study by Hinz et al. demonstrated 
that high-resolution ultrasound (HRUS) yielded a sensitivity of $12 \%(2 / 17)$ [28]. Chai et al. demonstrated a sensitivity of $34 \%$, but only 10 patients $(3.4 \%)$ could undergo US-FNAC prior to the surgical SN in their study [29]. The preliminary results of one larger series, pre-SN US-FNAC in the MSLT-2 study, reported sensitivity of merely $4.2 \%(8 / 193)$ [24].

Possible causes for these differences can be sought in the threshold for performing of a FNAC, which might be much higher in these studies. If we had performed a FNAC only in those cases with either BS or LCE reflecting the later and late signs, the sensitivity would have been as low as $24 \%$, which is exactly comparable to these other series.

Regarding survival, a study by Pilko et al. showed lower SN tumour burden and improved survival for US negative patients compared to US positive patients, even in the absence of a positive FNAC [30]. This is in line with our observation that US negative (no suspicious or malignant morphology criteria) patients have the best prognosis compared to PP only with a slightly decreased survival and a low survival rate for BS and/ or LCE (Fig. 2A/B) having in mind that sensitivity of US was $71 \%$ in the present study.

Looking to other types of cancer, ultrasound guidedFNAC staging is commonly applied as routine staging in breast and thyroid cancers [31-33]. In comparison, a meta-analysis by Alvarez et al. described ultrasound sensitivity for non-palpable lymph node metastases in breast cancer ranging from $48.8 \%$ to $87.1 \%$ with specificity ranging from $55.6 \%$ to $97.3 \%$. When the morphology of a lymph node was used, the sensitivity ranged from $26.4 \%$ to $75.9 \%$ with a specificity of $88.4 \%$ to $98.1 \%$ $[34,35]$. These rates are considered sufficient to apply the modality to the pre-operative work-up for breast cancer patients.

There is an ongoing discussion, whether patients with a minimal tumour load in the SN do really benefit from subsequent CLND. To date several studies like MSLT-2 and the EORTC 1208 (Minitub) are being performed to investigate whether CLND can be spared in these patients [36,37].

We envision that ultrasound guided FNAC can play a role in the future diagnostic algorithm of primary stage I/II melanoma patients (Fig. 4). As an addendum to the SLNB, US-guided FNAC is a pre-screening to enable a one-time setting, so that US-guided FNAC positive patients directly undergo completion lymph node dissection (CLND). Thus it can give early staging information of non-SLN involvement. Since Ultrasound or Ultrasound-guided FNAC negative patients will anyway undergo SLNB, no patient will be overlooked. Moreover, SLNB is an operation with concomitant morbidity and a false negative rate between $9 \%$ and $21 \%$ [38].

To validate our results in a multicenter, multi-observer fashion, we have undertaken our first EORTC Melanoma
Group sentinel node ultrasound course in 2012 to educate others in Berlin Morphology criteria.

\section{Conflict of interest statement}

None declared.

\section{Acknowledgements}

Supported by: Deutsche Krebshilfe (grant: 70-2791Vo I).

\section{References}

[1] Baade P, Meng X, Youlden D, Aitken J, Youl P. Time trends and latitudinal differences in melanoma thickness distribution in Australia, 1990-2006. Int J Cancer 2012;130(1):170-8.

[2] Simard EP, Ward EM, Siegel R, Jemal A. Cancers with increasing incidence trends in the United States: 1999 through 2008. CA Cancer J Clin 2012. http://dx.doi.org/10.3322/caac.20141 [Epub ahead of print].

[3] Forsea AM, Del Marmol V, de Vries E, Bailey EE, Geller AC. Melanoma incidence and mortality in Europe: new estimates, persistent disparities. Br J Dermatol 2012;167(5):1124-30.

[4] Hollestein LM, van den Akker SA, Nijsten T, Karim-Kos HE, Coebergh JW, de Vries E. Trends of cutaneous melanoma in The Netherlands: increasing incidence rates among all Breslow thickness categories and rising mortality rates since 1989. Ann Oncol 2012;23(2):524-30.

[5] Balch CM, Gershenwald JE, Soong SJ, Thompson JF, Atkins MB, Byrd DR, et al. Final version of 2009 AJCC melanoma staging and classification. J Clin Oncol 2009;27(36):6199-206.

[6] van der Ploeg AP, van Akkooi AC, Schmitz PI, Koljenovic S, Verhoef C, Eggermont AM. EORTC Melanoma Group sentinel node protocol identifies high rate of submicrometastases according to Rotterdam Criteria. Eur J Cancer 2010;46(13):2414-21.

[7] Morton DL, Thompson JF, Cochran AJ, Mozzillo N, Elashoff R, Essner R, et al. Sentinel-node biopsy or nodal observation in melanoma. N Engl J Med 2006;355(13):1307-17.

[8] Biver-Dalle C, Puzenat E, Puyraveau M, Delroeux D, Boulahdour H, Sheppard F, et al. Sentinel lymph node biopsy in melanoma: our 8-year clinical experience in a single French institute (2002-2009). BMC Dermatol 2012;12:21.

[9] Wrightson WR, Wong SL, Edwards MJ, Chao C, Reintgen DS, Ross MI, et al. Complications associated with sentinel lymph node biopsy for melanoma. Ann Surg Oncol 2003;10(6):676-80.

[10] Voit C, Kron M, Schafer G, Schoengen A, Audring H, Lukowsky A, et al. Ultrasound-guided fine needle aspiration cytology prior to sentinel lymph node biopsy in melanoma patients. Ann Surg Oncol 2006;13(12):1682-9.

[11] Voit CA, van Akkooi AC, Schafer-Hesterberg G, Schoengen A, Schmitz PI, Sterry W, et al. Rotterdam Criteria for sentinel node (SN) tumor burden and the accuracy of ultrasound (US)-guided fine-needle aspiration cytology (FNAC): can US-guided FNAC replace SN staging in patients with melanoma? J Clin Oncol 2009;27(30):4994-5000.

[12] Voit C, Van Akkooi AC, Schafer-Hesterberg G, Schoengen A, Kowalczyk K, Roewert JC, et al. Ultrasound morphology criteria predict metastatic disease of the sentinel nodes in patients with melanoma. J Clin Oncol 2010;28(5):847-52.

[13] Morton DL, Thompson JF, Cochran AJ, Mozzillo N, Nieweg OE, Roses DF, et al. Final trial report of sentinel-node biopsy versus nodal observation in melanoma. N Engl J Med 2014; 370(7):599-609. 
[14] Pasquali S, Mocellin S, Mozzillo N, Maurichi A, Quaglino P, Borgognoni L, et al. Nonsentinel lymph node status in patients with cutaneous melanoma: results from a multi-institution prognostic study. J Clin Oncol 2014;32(9):935-41.

[15] Dewar DJ, Newell B, Green MA, Topping AP, Powell BW, Cook MG. The microanatomic location of metastatic melanoma in sentinel lymph nodes predicts nonsentinel lymph node involvement. J Clin Oncol 2004;22(16):3345-9.

[16] van Akkooi AC, de Wilt JH, Verhoef C, Schmitz PI, van Geel AN, Eggermont AM, et al. Clinical relevance of melanoma micrometastases $(<0.1 \mathrm{~mm})$ in sentinel nodes: are these nodes to be considered negative? Ann Oncol 2006;17(10):1578-85.

[17] van der Ploeg AP, van Akkooi AC, Rutkowski P, Nowecki ZI, Michej W, Mitra A, et al. Prognosis in patients with sentinel node-positive melanoma is accurately defined by the combined Rotterdam tumor load and Dewar topography criteria. J Clin Oncol 2011;29(16):2206-14.

[18] Schoengen A, Binder T, Faiss S, Weber L, Zeelen U. Fine needle aspiration cytology of metastatic malignant melanoma. Improvement of results with ultrasound control. Hautarzt 1993;44(11): 703-7.

[19] Deperalta DK, Hoang MP, Tanabe KK. Approaches to regional nodes in patients with melanoma. J Clin Oncol 2014;32(9):881-5.

[20] Morton DL, Cochran AJ, Thompson JF, Elashoff R, Essner R, Glass EC, et al. Sentinel node biopsy for early-stage melanoma: accuracy and morbidity in MSLT-I, an international multicenter trial. Ann Surg 2005;242(3):302-11 [discussion 11-3].

[21] de Vries M, Vonkeman WG, van Ginkel RJ, Hoekstra HJ. Morbidity after inguinal sentinel lymph node biopsy and completion lymph node dissection in patients with cutaneous melanoma. Eur J Surg Oncol 2006;32(7):785-9.

[22] McMasters KM, Noyes RD, Reintgen DS, Goydos JS, Beitsch PD, Davidson BS, et al. Lessons learned from the Sunbelt Melanoma Trial. J Surg Oncol 2004;86(4):212-23.

[23] van Akkooi AC, Voit CA, Verhoef C, Eggermont AM. Potential cost-effectiveness of US-guided FNAC in melanoma patients as a primary procedure and in follow-up. Ann Surg Oncol 2010; 17(2):660-2.

[24] Morton DL, Cochran AJ, Thompson JF. The rationale for sentinel-node biopsy in primary melanoma. Nat Clin Pract Oncol 2008;5(9):510-1.

[25] Rossi CR, Mocellin S, Scagnet B, Foletto M, Vecchiato A, Pilati $\mathrm{P}$, et al. The role of preoperative ultrasound scan in detecting lymph node metastasis before sentinel node biopsy in melanoma patients. J Surg Oncol 2003;83(2):80-4.

[26] Starritt EC, Uren RF, Scolyer RA, Quinn MJ, Thompson JF. Ultrasound examination of sentinel nodes in the initial assessment of patients with primary cutaneous melanoma. Ann Surg Oncol 2005;12(1):18-23.
[27] van Rijk MC, Teertstra HJ, Peterse JL, Nieweg OE, Olmos RA, Hoefnagel CA, et al. Ultrasonography and fine-needle aspiration cytology in the preoperative evaluation of melanoma patients eligible for sentinel node biopsy. Ann Surg Oncol 2006;13(11): $1511-6$.

[28] Hinz T, Voth H, Ahmadzadehfar H, Hoeller T, Wenzel J, Bieber $\mathrm{T}$, et al. Role of high-resolution ultrasound and PET/CT imaging for preoperative characterization of sentinel lymph nodes in cutaneous melanoma. Ultrasound Med Biol 2013;39(1):30-6.

[29] Chai CY, Zager JS, Szabunio MM, Marzban SS, Chau A, Rossi RM, et al. Preoperative ultrasound is not useful for identifying nodal metastasis in melanoma patients undergoing sentinel node biopsy: preoperative ultrasound in clinically node-negative melanoma. Ann Surg Oncol 2012;19(4):1100-6.

[30] Pilko G, Zgajnar J, Music M, Hocevar M. Lower tumour burden and better overall survival in melanoma patients with regional lymph node metastases and negative preoperative ultrasound. Radiol Oncol 2012;46(1):60-8.

[31] de Kanter AY, van Eijck CH, van Geel AN, Kruijt RH, Henzen SC, Paul MA, et al. Multicentre study of ultrasonographically guided axillary node biopsy in patients with breast cancer. Br J Surg 1999;86(11):1459-62.

[32] Deurloo EE, Tanis PJ, Gilhuijs KG, Muller SH, Kroger R, Peterse JL, et al. Reduction in the number of sentinel lymph node procedures by preoperative ultrasonography of the axilla in breast cancer. Eur J Cancer 2003;39(8):1068-73.

[33] Leboulleux S, Girard E, Rose M, Travagli JP, Sabbah N, Caillou $\mathrm{B}$, et al. Ultrasound criteria of malignancy for cervical lymph nodes in patients followed up for differentiated thyroid cancer. J Clin Endocrinol Metab 2007;92(9):3590-4.

[34] Alvarez S, Anorbe E, Alcorta P, Lopez F, Alonso I, Cortes J. Role of sonography in the diagnosis of axillary lymph node metastases in breast cancer: a systematic review. AJR Am J Roentgenol 2006;186(5):1342-8.

[35] Abe H, Schmidt RA, Kulkarni K, Sennett CA, Mueller JS, Newstead GM. Axillary lymph nodes suspicious for breast cancer metastasis: sampling with US-guided 14-gauge core-needle biopsy-clinical experience in 100 patients. Radiology 2009; 250(1):41-9.

[36] van Akkooi AC, Verhoef C, Eggermont AM. Importance of tumor load in the sentinel node in melanoma: clinical dilemmas. Nat Rev Clin Oncol 2010;7(8):446-54.

[37] van der Ploeg AP, van Akkooi AC, Verhoef C, Eggermont AM. Completion lymph node dissection after a positive sentinel node: no longer a must? Curr Opin Oncol 2013;25(2):152-9.

[38] van Akkooi AC, Voit CA, Verhoef C, Eggermont AM. New developments in sentinel node staging in melanoma: controversies and alternatives. Curr Opin Oncol 2010;22(3):169-77. 